\title{
Glandular odontogenic cyst: Report of a pediatric case in an uncommon location
}

\author{
Asha V', Nevica Baruah ${ }^{2}$, Saleha Jamadar ${ }^{3}$ \\ From ${ }^{1}$ Reader, Department of Oral Medicine and Radiology, The Oxford Dental College, Bengaluru, Karnataka, ${ }^{2}$ Dental Surgeon, Assam Cancer Care \\ Foundation, Guwahati, Assam ${ }^{3}$ Reader, Department of Oral and Maxillofacial Pathology, The Oxford Dental College, Bengaluru, Karnataka, India
}

\begin{abstract}
Glandular odontogenic cyst (GOC), first described by Padayachee and Van Wyk in 1987, is a rare odontogenic cyst of the jaw which is commonly prevalent in the fourth decade. Clinically, it commonly presents as an asymptomatic swelling in the mandibular anterior region. A conclusive diagnosis can be given through histopathological examination. GOC is found to have a high recurrence potential which requires regular follow-up. Here, a rare case of a 14-year-old boy is described who presented with a swelling in left mandibular posterior teeth.
\end{abstract}

Key words: Children, Cyst, Odontogenic, Swelling

A glandular odontogenic cyst (GOC) is a rare developmental cyst of the jaw [1]. It was first documented by Padayachee and Van Wyk in 1987 as a sialo-odontogenic cyst due to its resemblance with the botryoid odontogenic cyst with a glandular element [2]. The name "Glandular odontogenic cyst" was adopted by World Health Organization (WHO) [3] after Gardner in 1988 found the lining epithelium to be odontogenic in origin [4]. GOC is known to have a high recurrence potential and requires regular follow-up [1] as compared to other odontogenic cysts.

Radiographically, it presents as a unilocular or multilocular radiolucency with well-defined margins and scalloped borders [1]. Radiological findings are non-specific and may mimic other cysts. Hence, a definitive diagnosis can be made based on typical histopathological findings [5]. GOC is commonly seen in individuals in the fourth decade who commonly present with swelling associated with erupted teeth in the mandibular anterior region. This paper describes a rare case of a 14-year-old boy presenting with GOC associated with an impacted supernumerary tooth in the posterior mandible.

\section{CASE REPORT}

A 14-year-old male visited the outpatient department with a chief complaint of pain and swelling in the left lower third of the face for 2 weeks. He had visited a hospital a week before he visited the department where he was prescribed Augmentin-375 mg tds

\section{Access this article online}

Received - 07 January 2021

Initial Review - 23 January 2021

Accepted - 03 April 2021

DOI: $10.32677 /$ IJCR.2021.v07.i04.006 and analgesics for 3 days. As per the patient, the swelling had reduced in size after taking antibiotics. The patient did not reveal any other relevant past medical, dental, or habit history.

The patient's vital signs were found to be within normal limits. On extraoral examination, a well-defined swelling of size approximately $5 \mathrm{~cm} \times 3 \mathrm{~cm}$ was present on the left lower third of the face (Fig. 1a). The swelling was firm in consistency, non-tender on palpation with no increase in surface temperature. On intraoral examination, a bony protuberance was noted in the region of the attached gingiva of tooth number 35 (Fig. 1b) with mild tenderness on palpation in the buccal vestibule in relation to tooth number 34 and 35 .

Heat test for pulp vitality was performed using gutta-percha stick for tooth number 34 and 35 and the teeth elicited an immediate response suggestive of vital teeth. Fine needle aspiration cytology was performed which did not yield any fluid. Panoramic radiograph revealed an impacted supernumerary tooth with an incomplete root formation in between the apices of 35 and 36 (Fig. 2). A welldefined radiolucency with a corticated margin and an approximate diameter of $2 \mathrm{~cm}$ involving the apex of 35 and the mesial side of the supernumerary tooth was observed. Cone beam computed tomography (CBCT) was advised to visualize the extensions. Sagittal sections of CBCT volume revealed loss of alveolar crestal bone between 35 and 36 and the radiolucency was seen to completely encircle the impacted supernumerary tooth and extend to involve the apical third of 35 (Fig. 3a). The axial section of the left mandible revealed perforation of the buccal cortical plate at the apical level of 35 (Fig. 3b). Preliminary hematological investigations were done before surgery which revealed normal values.

Correspondence to: Dr. Nevica Baruah, \#17, $5^{\text {th }}$ By lane, KKB Road, Chenikuthi, Guwahati - 781 003, Assam, India. E-mail: drnevicabaruah@gmail.com

(C) 2021 Creative Commons Attribution-NonCommercial 4.0 International License (CC BY-NC-ND 4.0). 


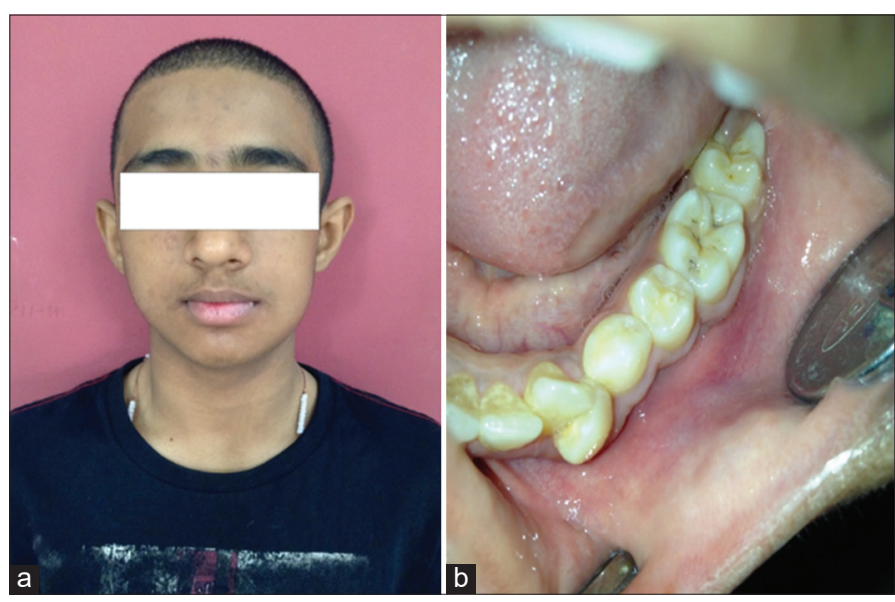

Figure 1: (a) Extraoral swelling on the left lower third of face; (b) bony protuberance noted in the region of attached gingiva of tooth number 35

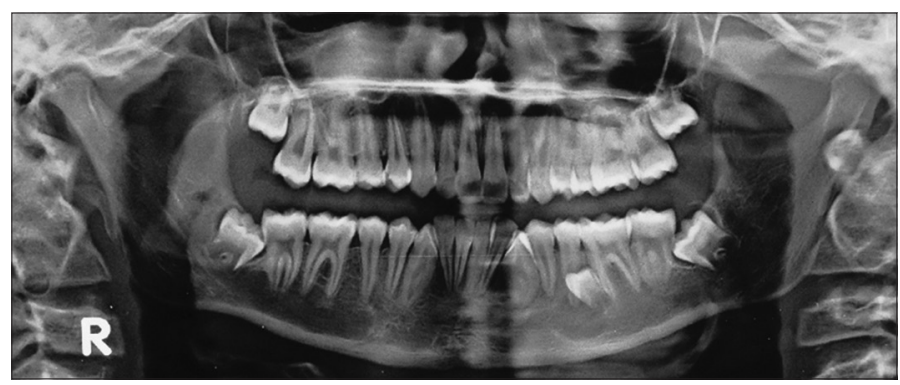

Figure 2: Panoramic radiograph showed a well-defined radiolucency with corticated margins involving apical third of tooth number 35 and mesial to impacted supernumerary tooth in relation to tooth number 35

Surgical enucleation of the cyst was performed together with removal of the supernumerary tooth and the cystic lining was sent for histopathological examination. On histopathological examination, a non-keratinized stratified squamous epithelium with superficial ciliated columnar cells was revealed (Fig. 4). In focal areas, the epithelial lining showed small microcysts, clear cells, and epithelial plaques. The interface between the epithelium and fibrous connective tissue wall was flat. Corroborating with clinical, radiological, and histologic findings, a diagnosis of GOC was given. The patient was informed to visit regularly at an interval of 3 months as recurrence is common in the GOC.

\section{DISCUSSION}

The GOC was defined by the WHO in 1992 as "a cyst arising in the tooth-bearing areas of the jaws and characterized by an epithelial lining with cuboidal or columnar cells both at the surface and lining crypts or cyst-like spaces within the thickness of the epithelium [4]." It is an uncommon cyst of the jaw and accounts for $0.012 \%-0.3 \%$ of all the odontogenic cysts [5]. Clinically, GOC is seen more commonly in individuals in the fourth decade. It is prevalent in both males and females, but males tend to be affected at a younger age than females [6]. It commonly occurs in the mandibular anterior region and presents as an asymptomatic slow-growing swelling [7].
A systematic review of GOC cases revealed that only $11 \%$ of the cases were associated with unerupted teeth. Since it is mostly seen in the anterior sextant of both jaws, the minimal association of GOC with unerupted teeth can be explained as the maximum number of cases is distant from the most commonly unerupted teeth, the third molars [8]. The case reported in this paper is of a rare instance of a 14-year-old boy who presented with GOC with respect to an unerupted supernumerary tooth in the posterior mandible.

Clinical diagnosis of GOC is challenging. The most common clinical finding is swelling which may be associated with pain [9]. As suggested by Krishnamurthy et al., a pre-operative aspiration biopsy may be helpful in diagnosing GOC, but in our case, it was negative. The aspiration fluids reported in the literature include clear with low viscosity, creamy high-viscosity, and brownish-red liquids [10].

Radiographically, the lesions typically presented as a radiolucent unilocular or multilocular lesion with well-defined cortical margins with frequent cortical bone perforations suggesting its aggressiveness [11]. Differential diagnosis of GOC may include dentigerous cyst, lateral periodontal cyst (LPC), and keratocystic odontogenic tumor. Although the radiological findings are non-specific, it plays an important role in the management of GOC. Panoramic radiography can be opted to view the lesion as it is less expensive and causes low radiation exposure. However, the superimposition of the image and the inability to view the buccolingual extension limits its use.

$\mathrm{CBCT}$ can be alternatively used as it provides a high-resolution three-dimensional image which gives information on the extent of the lesion, bone expansion, and the involvement of neighboring structures with less radiation exposure compared to other threedimensional imaging like conventional CT. Furthermore, CBCT was found to be fairly accurate in measuring osseous components, with $<1 \%$ error as compared to the gold standard method [12], and therefore, an accurate measurement of lesion aids in surgical management. CBCT images obtained in the case reported here allowed the margins and extent of the lesion, adjacent structures, and cortical bone perforation to be visualized.

Both conservative and aggressive approaches have been mentioned in the literature for the treatment of GOCs [11,13-16]. Conservative methods include enucleation, marsupialization, curettage with and without peripheral ostectomy, curettage with adjuvant Carnoy's solution, or cryotherapy. Recently, several authors recommended a more aggressive approach (marginal resection to partial jaw resection) as the treatment of choice of GOCs [14-16]. Furthermore, the cases treated with an aggressive approach were found to have no recurrences compared to cases treated with a conservative approach, as mentioned by Kaplan et al. [11]

Histopathological diagnosis of GOC is challenging as it mimics LPCs and low-grade mucoepidermoid carcinoma (MEC) [9]. Microscopic features of GOC include focal epithelial thickening, epithelial plaques, and glycogen-rich cells. These features are also seen in LPCs. However, LPCs do not exhibit the columnar ciliated surface cells and mucin pools seen in GOC. The histopathological features of GOC may also overlap with that of predominantly cystic intraosseous MEC. The epithelial lining 

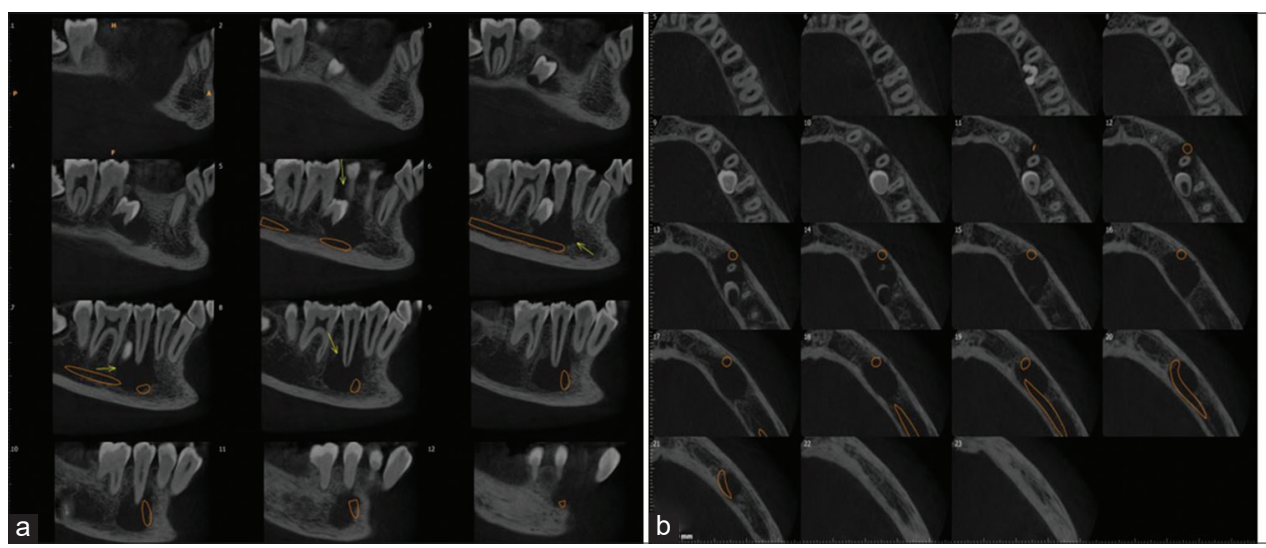

Figure 3: (a) Cone beam computed tomography (CBCT) images of the left posterior mandible. Sagittal section revealed a well-defined radiolucency involving apical third of tooth number 35 and completely encircling an impacted supernumerary tooth with loss of alveolar crestal bone in between tooth number 35 and 36; (b) Axial section of CBCT images revealed perforation of buccal cortical plate at the apical level of 35

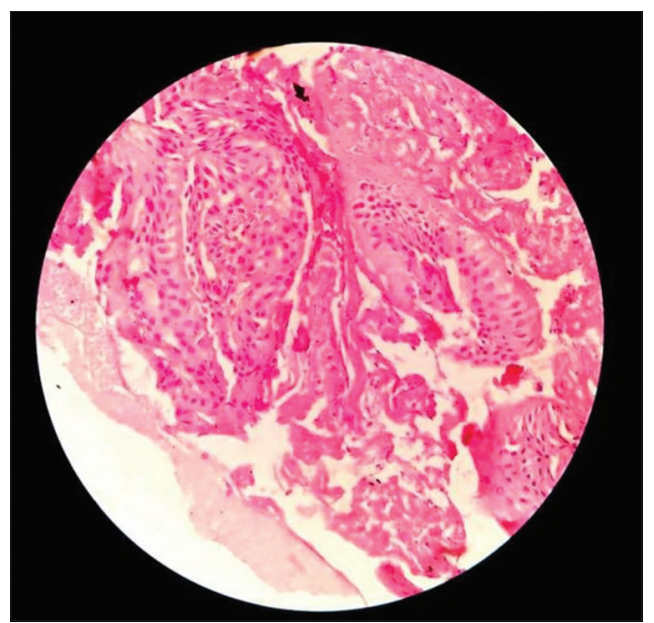

Figure 4: Histopathological examination revealed non keratinized stratified squamous epithelium with superficial ciliated columnar cells. Furthermore, few goblet cells, clear cells, and epithelial plaques were observed

of GOC is thinner and does not show evidence of more solid/ microcystic epithelial proliferation seen in MEC [17].

The recurrence rate of GOC has been reported to be high, approximately $21-30 \%[6]$ and it can be attributed to the thin lining, multilocularity of the cyst, the presence of microcysts, and high mitotic capacity of cells similar to a keratocystic odontogenic tumor [5]. As stated by Kaplan et al., further surgery is not indicated if the cyst is small (occupying $<2$ teeth) [11] and completely enucleated as there are fewer chances of recurrence in these cases. However, patients should be kept under follow-up for a minimum of 3 years [5].

\section{CONCLUSION}

A GOC is a rare cyst of the jaw and uncommon in children. It should be considered as a differential diagnosis in children as it is important to keep the patient on follow-up due to its high recurrence rate.

\section{REFERENCES}

1. Faisal M, Ahmad SA, Ansari U. Glandular odontogenic cyst-literature review and report of a paediatric case. J Oral Biol Craniofac Res 2015;5:219-25.
2. Padayachee A, van Wyk CW. Two cystic lesions with features of both the botryoid odontogenic cyst and the central mucoepidermoid tumour: Sialoodontogenic cyst? J Oral Pathol 1987;16:499-504.

3. Gardner DG, Kessler HP, Morency R, Schaffner DL. The glandular odontogenic cyst: An apparent entity. J Oral Pathol 1988;17:359-66.

4. Kramer IRH, Pindborg JJ, Shear M. Histological typing of odontogenic tumours. In: WHO International Histological Classification of Tumours. $2^{\text {nd }}$ ed. London: Springer-Verlag; 1992. p. 38.

5. Poudel P, Srii R, Chaurasia N, Upadhyaya C. Glandular odontogenic cystreport of a rare case. Clin Case Rep 2020;8:351-4.

6. Frazier JJ, Flint DJ. Glandular odontogenic cyst of the anterior maxilla in a 13-year old male: A rare case of location and age. J Oral Med Toxicol 2017;1:10-3.

7. Gurler G, Al-Ghamian H, Aksakalli N, Delilbasi C. Glandular odontogenic cyst: Case series. Contemp Clin Dent 2017;8:653-7.

8. Macdonald-Jankowski DS. Glandular odontogenic cyst: Systematic review. Dentomaxillofac Radiol 2010;39:127-39.

9. Shaik K, Reddy V, Ramesh, Chari H. A case report of glandular odontogenic cyst of mandible. Oral Health Care 2018;3:1-4.

10. Ferreira JC, Vêncio EF, de Sá RT, Gasperini G. Glandular odontogenic cyst in dentigerous relationship: An uncommon case report. Case Rep Dent 2019;2019:8647158.

11. Kaplan I, Anavi Y, Hirshberg A. Glandular odontogenic cyst: A challenge in diagnosis and treatment. Oral Dis 2008;14:575-81

12. Deana NF, Alves N. Cone beam CT in diagnosis and surgical planning of dentigerous cyst. Case Rep Dent 2017;2017:7956041.

13. Magnusson B, Goransson L, Odesjo B, Gröndahl K, Hirsch JM. Glandular odontogenic cyst. Report of seven cases. Dentomaxillofac Radiol 1997;26:26-31

14. Shen J, Fan M, Chen X, Wang S, Li W, Li Y. Glandular odontogenic cyst in China: Report of 12 cases and immunohistochemical study. J Oral Pathol Med 2006;35:175-82.

15. Kaplan I, Gal G, Anavi Y, Manor R, Calderon S. Glandular odontogenic cyst: Treatment and recurrence. J Oral Maxillofac Surg 2005;63:435-41.

16. Thor A, Warfvinge G, Fernandes R. The course of a long-standing glandular odontogenic cyst: Marginal resection and reconstruction with particulated bone graft, platelet-rich plasma, and additional vertical alveolar distraction. J Oral Maxillofac Surg 2006;64:1121-8.

17. Gnepp RD. Gnepp's Diagnostic Surgical Pathology of the Head and Neck. $2^{\text {nd }}$ ed. Philadelphia, PA: Saunders, Elsevier; 2009.

Funding: None; Conflicts of Interest: None Stated.

How to cite this article: Asha V, Baruah N, Jamadar S. Glandular odontogenic cyst: Report of a pediatric case in an uncommon location. Indian J Case Reports. 2021;7(4):143-145. 